\title{
Cervical remodeling in term and preterm birth: insights from an animal model
}

\author{
Mala Mahendroo \\ Department of Obstetrics and Gynecology and The Cecil H. and Ida Green Center for Reproductive Biology Sciences, \\ UT Southwestern Medical Center, 5323 Harry Hines Boulevard, Dallas, Texas 75235, USA
}

Correspondence should be addressed to M Mahendroo who is now at Department of Obstetrics and Gynecology, The University of Texas Southwestern Medical Center, 5323 Harry Hines Boulevard, Dallas, Texas 75390-9032, USA;

Email: mala.mahendroo@utsouthwestern.edu

\begin{abstract}
Proper cervical function is essential for a normal pregnancy and birth to occur. Understanding the mechanisms that take place in normal pregnancy will allow a better comprehension of the complications involved in premature cervical remodeling and lead to better methods of diagnostics and prevention for preterm birth. Unfortunately, human samples are not easily available, and samples that are collected are often confounded by variations in timing and region of cervix from which sample is collected. Animal models, specifically the mouse, have facilitated a great deal of exploration into the mechanisms of cervical function and pathways of preterm birth. This review highlights some of the groundbreaking discoveries that have arisen from murine research including 1) the identification of early pregnancy changes in collagen fibril processing and assembly that result in progressive modifications to collagen architecture with subsequent loss of tissue stiffness during pregnancy, 2) the determination that immune cells are not key to cervical ripening at term but have diverse phenotypes and functions in postpartum repair, and 3) the finding that the process of preterm cervical ripening can differ from term ripening and is dependent on the etiology of prematurity. These findings, which are relevant to human cervical biology, provide new insights that will allow targeted studies on the human cervix as well as identify potential biomarkers for early detection of premature cervical ripening and development of improved therapies to prevent premature ripening of the cervix and subsequent preterm birth.
\end{abstract}

Reproduction (2012) 143 429-438

\section{Introduction}

During pregnancy, the cervix remains closed and firm in order to prevent passage of an immature infant through the birth canal. Conversely, at term the cervix must become pliable and open sufficiently to allow delivery of a term fetus. While functionally distinct from the uterus, remodeling of the cervix must be appropriately coordinated with the onset of uterine contractility to ensure successful parturition. Investigations aimed at understanding these essential yet unique processes are required in order to understand the causes of preterm birth, which occurs at an alarming rate of $12.7 \%$ of all births (Martin 2011).

In recent years, investigations focused on the molecular mechanisms of cervical remodeling in the murine model have advanced our understanding of this dynamic process. The advantages of this model in the cervical biology field are numerous and include 1) the ability to obtain well-timed cervical tissue at all time points in the 19-day pregnancy, 2) the availability of mice with targeted mutations, 3) the fact that loss of progesterone $\left(\mathrm{P}_{4}\right)$ function culminates in the onset of labor in human and mouse, and 4) a growing body of evidence that many of the processes that occur during stages of cervical remodeling are similar in mouse and human. This review will highlight studies on the pregnant rodent cervix and provide a rationale as to how they contribute insights into human cervical biology.

\section{Cervical architecture}

The cervical stroma comprised primarily fibroblasts and to a lesser extent smooth muscle cells (Leppert 1995). These cells secrete an extracellular matrix (ECM) rich in fibrillar collagen, matricellular proteins, elastin, glycosaminoglycans, and proteoglycans. Changes in the ECM composition over the course of pregnancy and labor determine flexibility and mechanical strength of the cervix. Both the inner os (endocervix) and outer region of the cervix (exocervix) are lined with squamous mucosal epithelia. The uppermost region of the endocervix is lined with columnar epithelia, and this squamocolumnar junction delineates the boundary between uterine and cervical tissue. Resident immune cells 
including neutrophils, eosinophils, and macrophages are present in the cervix though their localization and relative numbers change over the course of pregnancy (Timmons \& Mahendroo 2006, Read et al. 2007). All these cell types have specific functions during pregnancy and parturition that are in part regulated by the steroid hormone environment. The maintenance of pregnancy requires that $\mathrm{P}_{4}$ levels are high and estrogen $\left(E_{2}\right)$ levels are relatively low resulting in an increased $P_{4} / E_{2}$ ratio. Increased $E_{2}$ levels in the latter third of gestation and a decline in $\mathrm{P}_{4}$ function in the day or two preceding parturition in mice results in a decline in the $\mathrm{P}_{4} / \mathrm{E}_{2}$ ratio. The reduced $\mathrm{P}_{4} / \mathrm{E}_{2}$ ratio is a hallmark of parturition and begins the cascade of accelerated cervical changes responsible for the final loss of structural integrity necessary for the safe passage of the fetus.

The initiation of cervical remodeling was once considered a passive process that was initiated and induced with the onset of uterine contractions at term. Since that time, research by many investigators has confirmed that cervical remodeling is a dynamic process that begins long before the onset of uterine contractions. The cervical remodeling process can be divided into four overlapping phases termed softening, ripening, dilation, and postpartum repair (Read et al. 2007).

\section{Cervical softening: progressive, incremental changes in ECM structure}

Cervical softening is defined as the first measurable increase in tissue distensibility when compared with the nonpregnant cervix and occurs by gestation day 12 in the mouse and rat (Harkness \& Harkness 1959, Read et al. 2007). Once initiated, there is a slow incremental decline in the tissue stiffness that is maximal at the time of birth (Mahendroo et al. 1999, Word et al. 2005). The $\mathrm{P}_{4} / \mathrm{E}_{2}$ ratio remains high during this phase and the tissue integrity is maintained despite the increased tissue compliance.

Fibrillar collagen types I and III are the main structural proteins in the cervix responsible for mechanical strength (Leppert 1995). Changes in the ratio of type I to III collagen, alterations in the multistep process of posttranscriptional processing of collagen monomers, and/or the assembly of collagen monomers into collagen fibrils can affect collagen structure and tissue mechanical strength (Kadler et al. 1996, Liu et al. 1997, Myers et al. 2010). Previous studies on the murine pregnant cervix documented an increase in collagen solubility during cervical softening with no change in total collagen content. This suggested the potential for regulated alterations in collagen processing during cervical softening (Read et al. 2007). While collagen solubility is an indirect indicator of collagen structure, evidence to support downregulation of specific steps in the collagen-processing pathway is mounting (Fig. 1).
This evidence includes a decline in cervical expression and/or activity of lysyl hydroxylase and lysyl oxidase (LOX), respectively, early in pregnancy and a subsequent decline in collagen containing the stronger pyridinoline cross-links in the second half of gestation (Ozasa et al. 1981, Akins et al. 2011). Cross-links between collagen molecules are essential in providing strength to the resulting collagen fibers and tissues (Eyre et al. 1984). Lysyl hydroxylase is an ER-resident enzyme that adds hydroxyl groups to lysine residues in the procollagen chain. The degree of hydroxylation determines the type and strength of potential cross-links that will be formed extracellularly. In the extracellular space, LOX catalyzes the formation of cross-links that occur between hydroxylated and/or nonhydroxylated lysine residues in collagen, resulting in the stronger pyridinoline or weaker nonpyridinoline cross-links respectively. A reduction in collagen cross-linking has been shown to reduce mechanical strength of the resulting tissue (Eyre et al. 1984, Canty \& Kadler 2005). This suggests that reduced cross-linking in the cervix during softening plays a role in the reduced mechanical strength of the cervix seen at this time. Equally important in this study was the finding that the ratio of the fibrillar collagens, type I and type III, remains constant throughout pregnancy, and thus alterations in I to III ratio is unlikely to be an important mechanism for the progressive decline in tissue stiffness (Akins et al. 2011). Furthermore, collagen turnover appears upregulated throughout pregnancy. In support of this idea, collagen I and III synthesis is robust, steps in processing appear upregulated to accommodate increased collagen turnover (e.g. C-terminal and $\mathrm{N}$-terminal processing of procollagen), and collagen content remains constant throughout pregnancy and parturition. While the activity of matrix metalloproteases (MMPs) that breakdown collagen have not been reported in the cervix during the softening period, it is likely that there is a constant breakdown of collagen to maintain steady collagen levels and facilitate progressive replacement of mature collagen fibrils with the newly synthesized, poorly cross-linked collagen.

In addition to collagen processing, collagen fibril structure and tensile strength are regulated by the composition of additional molecules within the ECM. Matricellular proteins are a family of nonstructural proteins that modulate collagen function and cell-matrix interactions (Bornstein \& Sage 2002). Genes encoding two members of this family, thrombospondin 2 (Thbs2) and tenascin-C (TnC), are downregulated early in gestation and remain low until just before birth (Akins et al. 2011). Numerous studies including the evaluation of mice deficient in Thbs 2 indicate that this matricellular protein plays a role in cervical softening and in the formation of appropriately assembled collagen fibrils, regulates activity of $\mathrm{Mmp2}$, and is an inhibitor of angiogenesis in a variety of tissues (Kyriakides et al. 1998, Kokenyesi et al. 2004). The decline in cervical 


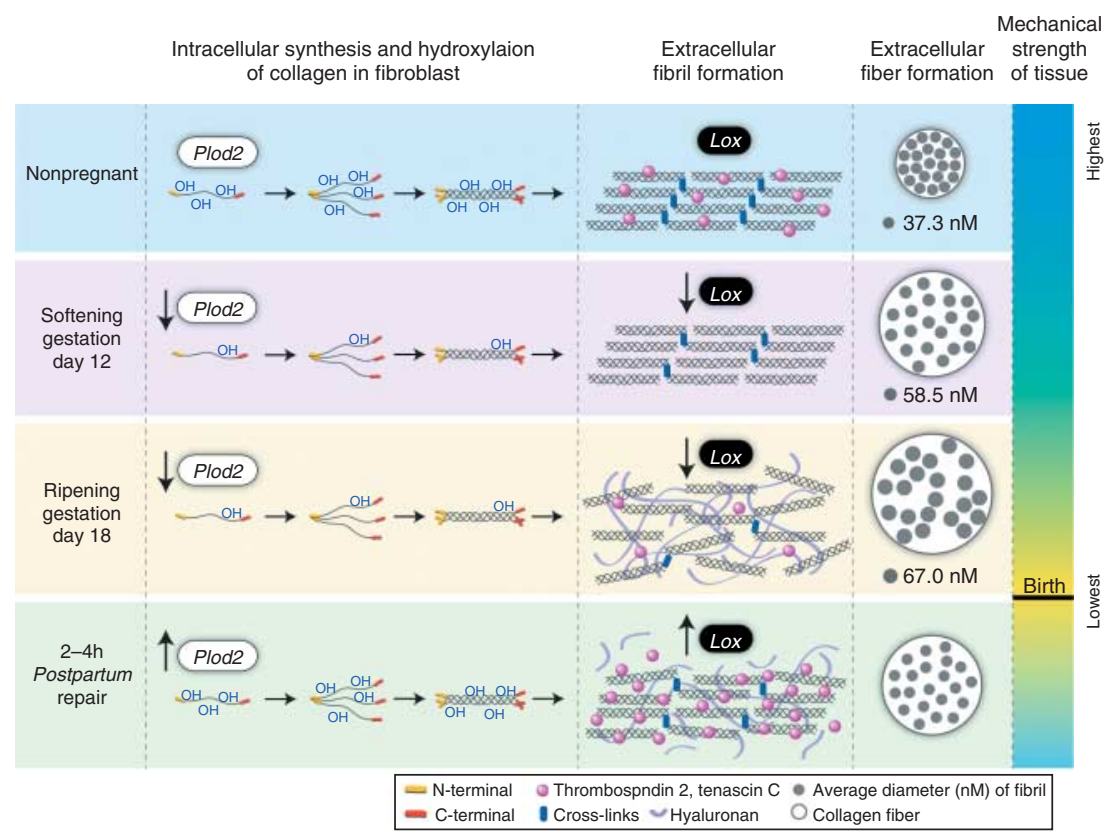

Figure 1 Progressive declines in cervical collagen cross-linking, thrombospondin 2 (THBS2), and tenascin C (TNC) that begin early in pregnancy contribute to formation of larger collagen fibers with reduced mechanical strength. The synthesis and assembly of collagen fibers is a multistep process in which procollagen monomers are synthesized intracellularly followed by $\mathrm{N}$ - and C-terminal processing and assembly into fibrils and fibers in the extracellular space. During pregnancy, both collagen synthesis and metabolism by proteases is elevated suggesting increased collagen turnover. Compared with the nonpregnant cervix, transcripts encoding enzymes important in cross-link formation, lysyl hydroxylase (Plod2) and lysyl oxidase (Lox) are downregulated by gestation day 8 of pregnancy. In addition, the expression of two matricellular proteins, THBS2 and TNC, declines in a similar timeframe. In an environment of increased collagen turnover, these early pregnancy changes contribute to the progressive replacement of mature collagen with poorly cross-linked collagen resulting in the gradual increase in cervical collagen fibril diameter and fiber size and the subsequent gradual decline in mechanical strength of the tissue, which is lowest at the time of labor.

Thbs2 expression during pregnancy may contribute to alterations similar in collagen architecture and/or protease activity, which could also aid in the progressive decline in mechanical strength. The mechanism by which THBS2 regulates collagen architecture in the cervix as well as hormonal regulation of this process remains to be determined. Tnc is upregulated during tissue injury and has numerous reported roles that mediate both proinflammatory and fibrotic responses to mediate tissue repair (Midwood et al. 2011). Thus, downregulation of Tnc during pregnancy and marked induction shortly postpartum is consistent with Tnc's proposed functions in tissue injury. Taken together, the gradual replacement of mature cross-linked collagen with collagen harboring reduced cross-links along with the decline in THBS2 and TNC in the cervix is key to modulating collagen architecture within the ECM during softening and initiating the incremental fall in cervical mechanical strength while maintaining tissue integrity.

Along with the extensive changes in the cervical ECM during softening, the cervical epithelia may also play an important role during this time though our understanding of their roles in cervical remodeling remains to be defined. Epithelial functions include immunoprotection and maintenance of a barrier, which are likely important in the protection of the stromal compartment as the matrix remodels. During softening, these functions are exemplified by localization of immune cells to the epithelial/subepithelial regions of the cervix as well as the induction of proteins involved in restitution and repair of the cervical mucosal epithelia (Read et al. 2007). These include trefoil factor 1 (TFF1) and serine protease inhibitor Kazal type 5 (SPINK5). TFF1 is a secreted peptide first described in the gastric mucosa where its functions include protection and restitution of gut mucosal epithelia. Spink5 encodes a protease inhibitor expressed in stratified epithelia of the skin and functions to prevent degradation of proteins involved in barrier formation. While further studies are needed to define a function of TFF1 and SPINK5 in the cervix, the observation that transcripts encoding these proteins are upregulated during cervical softening suggests that the epithelia play an important function in protection and maintenance of cervical competency.

\section{Cervical ripening and dilation: accelerated phases of remodeling}

Given the short duration of the ripening and dilation phases, it is difficult to identify processes that distinguish these two overlapping phases of remodeling and thus they are presented jointly in this section. Unlike cervical softening, the ripening process is very rapid. Ripening is 
initiated on the last day of murine pregnancy (gestation day 18) and results in maximal loss of tissue compliance by late day 18 (Mahendroo et al. 1999). This phase occurs in a low $\mathrm{P}_{4} / \mathrm{E}_{2}$ environment and is accompanied by a loss of structural integrity. The importance of collagen structure to the biomechanical properties of the cervix has been appreciated for many years yet the mechanisms by which accelerated changes during ripening occur have been greatly debated. Numerous studies report a decline in collagen content resulting from increased activity of proteases as a key mechanism for loss of tissue integrity at term (Rajabi et al. 1991). Other experimental findings call this model into question including the observations that 1) collagen synthesis is upregulated during pregnancy, 2) biomechanical properties of cervices treated exogenously with collagenase differ from term ripening, and 3) changes in collagen structure and organization rather than abundance are observed by polarized light microscopy and transmission electron microscopy (Yu et al. 1995, Buhimschi et al. 2004, Akins et al. 2011). Studies on mice and rats indicate that while total collagen content is constant throughout pregnancy and parturition, collagen structure undergoes dynamic changes as determined by second harmonic generation (SHG), electron microscopy, and light-induced fluorescence (Yu et al. 1995, Maul et al. 2003, Akins et al. 2011). Collagen ultrastructure as observed in electron micrographs reveals a progressive increase in collagen fibril diameter in the cervix from early to late gestation along with increased spacing between fibrils (Fig. 1). Evaluation of collagen fiber structure by SHG microscopy reveals progressive changes in the morphological features of collagen type I fibers over the course of pregnancy (Akins et al. 2010). Most notable in SHG images is the transition from long thin collagen fibers to thicker curved fibers at term. These striking visual observations emphasize the progressive changes in collagen structure that likely begin with the reduction in cross-linked collagen and matricellular proteins during cervical softening. These changes are further built upon during ripening to allow for a maximal increase in the tissue compliance and loss of integrity of the cervix seen during dilation.

A notable feature of ripening that likely facilitates matrix disorganization is the increased synthesis of the glycosaminoglycan and hyaluronan (HA; Straach et al. 2005). Early in pregnancy cervical HA represents just $19 \%$ of total cervical glycosaminoglycans; however, at term this figure rises to $71 \%$ (Akgul et al. 2012). HA's functions are dependent on its size as well as its interactions with other HA-binding molecules. Large molecular weight HA is a hydrophilic, space-filling molecule that provides increased viscoelasticty to tissues while low-molecular weight $\mathrm{HA}$ has proinflammatory functions (Powell \& Horton 2005). During ripening, large molecular weight $\mathrm{HA}$ is elevated to facilitate increased spacing between collagen fibers and may contribute to the modest increase in tissue hydration (Ruscheinsky et al. 2008). As highlighted in the next section, low-molecular weight HA predominates during postpartum repair. HA is synthesized by HA synthases encoded by the genes Has 1, Has2, and Has3 and broken down by the enzyme hyaluronidase (HYAL) encoded by five genes (Hyal1-5) (Itano \& Kimata 1996, Spicer et al. 1996, Stern 2003). Cervical transcripts encoding Has2 are induced during ripening with peak expression on gestation day 18 (Straach et al. 2005). HA matrices are stabilized by interaction with other molecules such as the proteoglycan, versican, the cell surface receptor, CD44, and the serum protein, inter-alpha trypsin inhibitor (Ruscheinsky et al. 2008). Versican is localized to the cervical stromal matrix while CD44 is expressed in cervical epithelia as well as in immune cells. The presence of HA-rich matrices surrounding both the cervical mucosal epithelia and the stroma as well as cell-specific expression of HA-interacting molecules suggest that $\mathrm{HA}$ has multiple cell-specific functions during cervical ripening.

There is a marked proliferation of the mucosal epithelia in the latter half of rat pregnancy that is dependent on the actions of the hormones relaxin and $E_{2}$ (Lee et al. 2005). By gestation day 16 and 17 as the softening phase merges into the ripening phase, the epithelium becomes laden with mucin-secreting vacuoles important in immune surveillance and lubrication. During this time, the epithelia also express steroid 5 alpha reductase type 1 (Srd5a1) important in local $\mathrm{P}_{4}$ metabolism (Mahendroo et al. 1999). The loss of $P_{4}$ function resulting from the decline in $\mathrm{P}_{4}$ synthesis in the ovary along with increased $\mathrm{P}_{4}$ metabolism by SRD5A1 facilitates the transition to the cervical ripening phase of remodeling. During ripening, regulated changes in the barrier properties, hydration, and cell-to-cell communications are suggested by regulated expression of tight junction proteins (claudin 1 and 2), aquaporins, gap junction proteins (Connexin 26 and 43), and desmogleins (Anderson et al. 2006, Timmons \& Mahendroo 2007, Timmons et al. 2007, Gonzalez et al. 2009). Further studies are required to understand the important roles that the epithelia play in protecting the softened cervix and in orchestration of remodeling events that occur in the cervical stroma.

As discussed in Box 1, the overall labor process is considered to be an inflammatory process though recent investigations in the cervical biology field suggest that some aspects of parturition may not be regulated by an inflammatory response. Immune cells that infiltrate the cervix during cervical ripening have long been considered to play a key role in ECM degradation and remodeling via activation of proinflammatory signals and the release of MMPs that breakdown collagen (Liggins 1981). Numerous studies based on immunohistochemical analysis of immune cells suggest a functional role of macrophages or neutrophils in the process of 
Box 1 Is term labor an inflammatory response?

Several components make up the pregnant reproductive system: the uterus, cervix placenta, and fetal membranes. All have distinct compositions and functions but work together at term with a common goal birth. While these tissues are under the influence of the same steroid hormones, progesterone $\left(\mathrm{P}_{4}\right)$ and estrogen, the processes that allow successful parturition at term (e.g. uterine contractions, fetal membrane breakdown, and cervical remodeling) occur by distinct mechanisms. Current evidence supports a model in which some aspects of parturition are mediated by activation of inflammatory responses while other key components are not. $\mathrm{P}_{4}$ is an antiinflammatory agent and loss of $\mathrm{P}_{4}$ function at term results in activation of proinflammatory responses. This leads to activation of $\mathrm{NF}-\mathrm{\kappa B}$ and subsequent increases in contractile-associated proteins (e.g. oxytocin receptor and connexin-43) in the uterus, thus inducing myometrial contractility. Increased proinflammatory signals in the amniotic fluid also promote increased prostaglandin production in fetal membranes. Prostaglandins in turn increase expression of MMPs, allowing fetal membrane breakdown and rupture. In the term cervix, proinflammatory responses are not activated during ripening. Both proinflammatory and immunosuppressive responses are activated after onset of labor and thus likely to facilitate postpartum repair of the cervix. While unnecessary for term ripening, upregulation of proinflammatory cytokines and prostaglandin synthesis are sufficient to promote premature cervical ripening during infection-mediated preterm birth. After birth, cervical recovery and repair are necessary to protect the reproductive tract from environmental insults and ensure subsequent pregnancies. However, the functional use of the fetal membrane is completed at term and thus processes that induce degradation without repair are beneficial. We suggest a physiological advantage for these differing mechanisms. Current evidence suggests that some but not all aspects of labor is an inflammatory response.

cervical ripening (Junqueira et al. 1980, Luque et al. 1998, Mackler et al. 1999, Young et al. 2002, Osman et al. 2003). The fact that antibodies used for assessment of macrophages and neutrophils can also recognize monocytes and other myeloid cells and the recent appreciation that a single type of immune cell (e.g. macrophage) can have diverse phenotypes dependent on the microenvironment limits the conclusions that can be drawn from these reports. Evidence from our group and others suggest that activation of immune cells is not required for physiological ripening at term (Hirsch et al. 2006, Timmons \& Mahendroo 2006, Gonzalez et al. 2009, Timmons et al. 2009). During ripening there is an influx of monocytes into the cervix that are dependent on the loss of $\mathrm{P}_{4}$ function. In addition, resident macrophages and neutrophils are present in the cervix at this time. Despite the presence of these leukocytes, mRNA expression of proinflammatory genes such as $/ / 1$ a, $/ / 6$, Tnf, Cxcl1, Ptgs1 (Cox1), Ptgs2 (Cox2), and CxCl2 (Mip2) as well as MMPs such as Mmp2, Mmp8, and Mmp9 are not induced during ripening though a few are increased shortly postpartum. Furthermore, depletion of neutrophils has no effect on timing of parturition and myeloperoxidase activity, a marker of functional neutrophils, is not detectable until postpartum. These data suggest that immune cells are present but not activated during cervical ripening, thus leading our group and others to suggest that physiological ripening is not mediated by an inflammatory cascade. One notable exception is the increase in transcripts encoding the chemoattractant, eotaxin1 (Ccl10) on gestation day 18 followed by a significant increase in eosinophils in the cervix during labor. $/ 15$ deficiency in mice leads to a significant decrease in eosinophils in the cervix during cervical ripening though it has no effect on the timing of parturition (Robertson et al. 2000). While the function of eosinophils in the cervix remains to be determined, recent studies suggest that eosinophils promote the differentiation of monocytes into alternatively activated macrophages (M2) in adipose tissue, which are key in maintenance of glucose homeostasis (Wu et al. 2011). Eosinophils may have a similar function in the cervix to regulate monocyte differentiation and macrophage polarization during postpartum repair. As will be discussed in the next section, evidence to support activation of monocytes during labor or postpartum repair is accumulating.

\section{Postpartum recovery of the cervix: tissue repair}

The recovery of the cervix following birth must occur rapidly to ensure protection of the reproductive tract from environmental insults as well as to ensure the success of subsequent pregnancies. Gene microarray comparisons between ripening and shortly postpartum emphasize the dramatic and rapid changes that drive this transition (Timmons \& Mahendroo 2007, Gonzalez et al. 2009). These include changes in epithelial specific genes such as desmogleins and keratin 16 as well as inflammatory associated genes and genes involved in ECM synthesis, processing, and repair. In contrast to the cervical ripening phase, myeloid-derived immune cells likely play an important role in this phase of remodeling. Evidence in support of this hypothesis is the observation that neutrophil numbers and myeloperoxidase activity are increased as is expression of genes associated with classical proinflammatory M1 macrophages and alternatively activated M2 macrophages as early as $2 \mathrm{~h}$ 
postpartum. While further experimentation is required to confirm this hypothesis, we propose that monocytes entering the cervix during ripening are differentiated to macrophages and polarized to both $\mathrm{M} 1$ and $\mathrm{M} 2$ phenotypes with onset of labor or postpartum. This macrophage diversity allows removal of matrix 'debris' (e.g. HA, versican, and poorly assembled collagen), yet ensures rapid suppression of inflammatory responses that, if uncontrolled, would lead to further tissue damage. Consistent with the activation of proinflammatory responses during this phase is the increased activity of the HA metabolizing enzyme, hyaluronidase 1 , and subsequent increase in low-molecular weight $\mathrm{HA}$, which has reported functions in activation of proinflammatory responses (Ruscheinsky et al. 2008, Akgul et al. 2012). In tandem with matrix cleanup by immune cells, expression of genes that function in collagen synthesis and cross-linking (e.g. Col1a, Col3a, Plod2, and Lox) and metabolism of proteoglycans such as versican (e.g. Adamts1) and wound healing (e.g. Tnc and Thbs 1/2) are upregulated in the postpartum cervix. The combined action of these molecules promotes tissue repair and inhibition of angiogenesis (Bornstein \& Sage 2002, Timmons \& Mahendroo 2007, Midwood et al. 2011).

\section{Premature cervical ripening}

Effective therapies and tools for accurate detection of preterm birth is complicated by the fact that while there are a multitude of established causes for prematurity such as infection, environment, genetics, in roughly $50 \%$ of cases the cause is unknown. In most cases, premature cervical ripening precedes onset of preterm labor. This knowledge emphasizes the need to define the molecular processes that drive term and preterm cervical remodeling. While preterm birth was once considered an acceleration of the normal physiological process, evidence to support diverse mechanisms by which preterm birth can occur is mounting (Gross et al. 2000, Hirsch et al. 2006). Recent studies using two established mouse models of preterm birth have provided novel insights into distinct processes by which cervical ripening can occur. Animals administered lipopolysaccharide (LPS), found in the outer membrane of Gram-negative bacteria, elicit a proinflammatory response similar to infection and undergo preterm labor without a loss in circulating $\mathrm{P}_{4}$ concentration several hours after administration (Hirsch \& Muhle 2002, Elovitz \& Mrinalini 2004). Premature loss of $\mathrm{P}_{4}$ function by administration of a $\mathrm{P}_{4}$ receptor antagonist (RU486/ mifepristone) similarly results in onset of preterm labor within several hours after treatment. Gene microarray and expression comparisons between term and the infection-induced premature ripening model indicate that the activation of proinflammatory cascades is sufficient for infection-mediated preterm ripening but not necessary for term cervical ripening (Gonzalez et al. 2009).
Studies from our group (summarized in Table 1) are in agreement with these findings and confirm that cervical ripening can be initiated by more than one mechanism and is not necessarily an acceleration of the physiological process at term (Holt et al. 2011). Specifically, premature ripening induced by the $\mathrm{P}_{4}$ receptor antagonist, mifepristone, results from an acceleration of processes in place during term ripening as well as partial activation of proinflammatory and tissue repair processes observed during postpartum repair. In contrast to the mifepristone induced or term remodeling, premature ripening induced in an infection model occurs by a distinct mechanism, which is dominated by an influx of neutrophils in the cervix, a marked proinflammatory response, and increased expression of prostaglandin cyclooxygenase endoperoxide synthase 2 (Ptgs2). Interestingly, while the neutrophil collagenase MMP8 is upregulated in the infection model, total collagen content does not decline. The complement system is reported to play a role in activation of inflammatory responses in both preterm birth models as mice deficient in the complement receptor C5a do not deliver preterm in response to LPS or mifepristone treatment (Gonzalez et al. 2011). Taken together, these studies confirm that multiple mechanisms exist to facilitate cervical ECM remodeling and loss of tensile strength and that the mechanism is dependent on the etiology of prematurity.

\section{Relevance to cervical remodeling in women}

There are clearly notable distinctions between human and mouse physiology of pregnancy and parturition that suggest the molecular process of cervical remodeling is not identical in the two species. The fact that humans are bipedal compared with the quadruped mouse suggests the mechanisms to maintain cervical competence in the human may be more complex. In addition, the continued synthesis of $\mathrm{P}_{4}$ by the human placenta indicates that other mechanisms predominate in abrogating $\mathrm{P}_{4}$ function at the end of pregnancy in contrast to mice and other species in which luteolysis is key to loss of $\mathrm{P}_{4}$ function at term. There is potential for differences in epithelial cell function between species as the human cervix is composed of glandular epithelia and a columnar and squamous epithelia that line the endocervix and ectocervix, respectively, while the mouse does not have glandular epithelia and the endocervix and ectocervix is primarily composed of squamous epithelia with a small region of columnar epithelia in the endocervix. Given the recent appreciation of the important roles of epithelia in the maintenance of barrier properties and immune surveillance in mouse and human, a better understanding of these differences is needed (Timmons et al. 2010, Nold et al. 2012).

While well-designed studies using limited pregnant human cervix tissue will be required for our ultimate understanding of term and preterm cervical remodeling 
Table 1 Salient features of preterm and term ripening and postpartum repair compared with gestation day 15.

\begin{tabular}{|c|c|c|c|c|}
\hline & RU486 (d15) & LPS (d15) & Term (d18) & Postpartum (2-4 h) \\
\hline \multirow[t]{4}{*}{ Myeloid cells numbers } & $\uparrow$ Mo & $\leftrightarrow$ Mo & $\uparrow$ Mo & $\uparrow$ Mo \\
\hline & $\leftrightarrow \mathrm{Mac}$ & $\leftrightarrow \mathrm{Mac}$ & $\leftrightarrow \mathrm{Mac}$ & $\leftrightarrow \mathrm{Mac}$ \\
\hline & $\leftrightarrow \mathrm{Neu}$ & $\uparrow \mathrm{Neu}$ & $\leftrightarrow \mathrm{Neu}$ & $\uparrow \mathrm{Neu}$ \\
\hline & $\uparrow$ Eo & $\leftrightarrow$ Eo & $\leftrightarrow$ Eo & $\uparrow$ Eo \\
\hline Macrophage phenotype $^{a}$ & $\mathrm{M} 1$ and $\mathrm{M} 2$ & $\mathrm{M} 1$ and $\mathrm{M} 2$ & $\begin{array}{l}\text { Macphages present but no expression } \\
\text { of } \mathrm{M} 1 \text { and } \mathrm{M} 2 \text { markers }\end{array}$ & M1 and M2 \\
\hline Induced proinflammatory genes & IIla, Ptgs1 & $\begin{array}{l}\text { IIla, II6, Tnf, Cxcl2, } \\
\quad \text { Ptgs2 }\end{array}$ & Ccl11 (eotaxin- 1$)$ & $\begin{array}{l}\text { II1a, Tnf, Ccl2 } \\
\text { (Mcp1), Cxcl2 }\end{array}$ \\
\hline \multirow[t]{3}{*}{ Protease gene expression } & Mmp8 & Mmp8 & Adamts1 & Мmp8 \\
\hline & Adamts1 & Adamts1 & Adamts4 & Adamts 1 \\
\hline & Adamts4 & Adamts4 & & Adamts4 (ND) \\
\hline Total collagen content & No change & No change & No change & No change \\
\hline Hyaluronan synthase & $\uparrow$ Has1 & $\uparrow$ Has1 & $\uparrow$ Has2 & $\uparrow$ Has2 \\
\hline HA localization & Stromal matrix & Stromal matrix & Epithelial and stromal matrix & $\begin{array}{l}\text { Epithelial and stromal } \\
\text { matrix }\end{array}$ \\
\hline Average tissue ${ }^{\mathrm{b}}$ wet weight (mg) & 25.9 & 16.4 & 26.2 & 35.4 \\
\hline Progesterone function/levels & $\downarrow$ & $\leftrightarrow$ & $\downarrow$ & $\downarrow$ \\
\hline
\end{tabular}

ND, not determined.

a Based on gene expression of classical M1 macrophages (I/6, I/1a, Tnf, and CXCl2) and alternatively activated M2 macrophages (YM1 and I/1 rn).

${ }^{\mathrm{b}}$ Preterm birth induced on gestation day 15 . Untreated day 15 cervix average wet weight is $15.8 \mathrm{mg}$.

in women, the advances in our understanding of molecular events that modulate murine cervical remodeling provide insights that are likely to be relevant to human cervical biology. Similar to the mouse, early pregnancy changes in cervical compliance as determined by digital examination was noted over 100 years ago and was the basis for the Hegar score used to determine pregnancy before more sophisticated measurements. Furthermore, the importance of collagen processing and assembly in early pregnancy in women is highlighted by the fact that women with genetic defects in collagen and elastin synthesis or assembly (e.g. Ehlers-Danlos and Marfan syndromes) have an increased incidence of cervical insufficiency (Anum et al. 2009). These studies further suggest that polymorphisms associated with genes important for connective tissue synthesis and metabolism may predispose women to preterm birth due to cervical insufficiency or preterm premature rupture of membranes. On the other end of the spectrum, the failure to activate genes important in connective tissue remodeling could be an underlying cause of postterm pregnancies due to failure of cervical remodeling (Kistka et al. 2007). Another important similarity between mouse and human at this stage of remodeling is the fact that these changes occur during a period in which the $\mathrm{P}_{4}$ to $\mathrm{E}_{2}$ ratio is high in both species, thus hormonal regulation of these processes may be conserved. Future targeted studies are needed to evaluate the contribution of reductions in collagen cross-linking and matricellular proteins to physiological softening as well as the identification of specific mutations or polymorphisms in genes involved in connective tissue synthesis or degradation, which may contribute to either cervical insufficiency or postterm pregnancy due to failure of cervical ripening. Aberrant regulation of described processes important in cervical softening may also contribute to premature cervical shortening as determined by sonography, which is a risk factor for women with a previous history of preterm birth (Owen et al. 2001).

In both women and mice, cervical ripening and dilation are preceded by a decline in $\mathrm{P}_{4}$ function. In the mouse, loss of $\mathrm{P}_{4}$ function at term is achieved by a decline in ovarian $\mathrm{P}_{4}$ synthesis (Virgo \& Bellward 1974), increased local metabolism of $P_{4}$ (Mahendroo et al. 1996, 1999, Ishida et al. 2007), and a change in expression of $\mathrm{P}_{4}$ receptor isoforms and coactivators (Fang et al. 2002, Condon et al. 2003). In the human, circulating levels of $\mathrm{P}_{4}$ do not decline before birth due to its synthesis in the placenta. However, the remaining documented mechanisms for loss of $\mathrm{P}_{4}$ function, such as local $\mathrm{P}_{4}$ metabolism, changes in $\mathrm{P}_{4}$ receptor isoform and coactivator expression are conserved (Mesiano et al. 2002, Condon et al. 2003, Stjernholm-Vladic et al. 2004, Andersson et al. 2008). Furthermore, administration of $\mathrm{P}_{4}$ receptor antagonists such as mifepristone to women will induce cervical ripening and preterm birth, emphasizing the need for $\mathrm{P}_{4}$ to maintain pregnancy and loss of $\mathrm{P}_{4}$ function to initiate parturition (Elliott et al. 1998).

Processes that govern ripening and dilation appear common between mice and women. In both species, the glycosaminoglycan composition is altered over the course of pregnancy and likely modulates matrix organization (Maillot \& Zimmermann 1976, Osmers et al. 1993, Myers et al. 2009, Akgul et al. 2012). This includes increased concentration of HA in the stroma and mucus that ranges from high to low molecular weight and increased transcription of hyaluronidase 2 (Akgul et al. 2012). These observations suggest a similar function of high-molecular weight $\mathrm{HA}$ to support increased tissue hydration and collagen disorganization 
during ripening. The presence of low-molecular weight HA with onset of labor or postpartum may have specific functions in activation of proinflammatory responses as described in other systems (Jiang et al. 2005). The importance of HA breakdown to low-molecular weight $\mathrm{HA}$ is supported by reports that women treated with intracervical injections of hyaluronidase at term had a shorter duration of labor and increased rate of vaginal delivery compared with the placebo group (Spallicci et al. 2007). Similar findings are described in animal models (Byers et al. 2010). The size-specific functions of HA in ripening, dilation, and postpartum repair require further investigation as does the contribution of aberrant HA function or processing to preterm and postterm birth.

While a large body of literature suggests a key role of inflammation in mediating cervical ripening in women, many of these studies utilize tissues collected after prolonged labor or post-vaginal delivery at which time the gene expression profile is markedly altered compared with ripening (Young et al. 2002, Osman et al. 2003). Moreover, immunohistochemical analysis is complicated as most of the identifying surface markers such as CD68 in human or F4/80 in mice are found on multiple myeloid-derived cells (macrophages, monocytes, and eosinophils) as well as nonhematopoietic cells and thus the antibodies used cannot distinguish specific myeloid cell subtypes (Gordon \& Taylor 2005). In addition, the recent insight that a single type of myeloid cell can have a spectrum of phenotypes that range from proinflammatory to immunosuppressive (e.g. M1 and M2 macrophages), further muddies interpretation of immunohistochemical studies on human and animal models. The limited studies that utilize wellcharacterized tissues collected during ripening before birth suggest no increase in the proinflammatory chemoattractant, $1 / 8$, while microarray studies that compare gene expression patterns at term before ripening to postpartum reveal increased expression of proinflammatory genes after vaginal delivery but not during cervical ripening (Sakamoto et al. 2004, 2005, Hassan et al. 2006, 2009). Studies on mice in which precisely timed cervical tissue can be obtained before, during, and after term cervical ripening, the use of more sophisticated technologies to allow identification of myeloid cells via multiple surface markers and identification of markers that distinguish macrophages of varying phenotypes have been instrumental in clarifying the contribution of immune cells to both physiological and pathophysiological remodeling and emphasize the need to reevaluate more critically the role of immune cells in human term cervical ripening. Further investigations are warranted using available human tissues from term- and infection-induced preterm birth samples in order to develop targeted therapies or identify biomarkers that may be predictive of this subset of PTB.

\section{Summary}

While much work remains, our understanding of the molecular processes that drive cervical remodeling has advanced in recent years. Incremental and cumulative changes in the ECM occur in a $\mathrm{P}_{4}$-rich environment during softening with further rapid and more aggressive changes to the ECM upon loss of $\mathrm{P}_{4}$ function during cervical ripening and dilation. To complete the loop of remodeling and allow subsequent pregnancy, proinflammatory and immunosuppressive processes modulate tissue repair postpartum. Dynamic, cumulative changes in the cervical ECM are initiated early in pregnancy and culminate in the formation of a highly disorganized ECM of unique composition that allows for the loss of tissue integrity resulting in cervical opening during parturition.

\section{Declaration of interest}

The author declares that there is no conflict of interest that could be perceived as prejudicing the impartiality of the review.

\section{Funding}

This work is supported by NIH R01 HD043154, P0111149, and The Hartwell Foundation.

\section{References}

Akgul Y, Holt R, Mummert M \& Mahendroo M 2012 Dynamic changes in cervical glycosaminoglycan composition during normal pregnancy and preterm birth. Endocrinology [in press].

Akins ML, Luby-Phelps K \& Mahendroo M 2010 Second harmonic generation imaging as a potential tool for staging pregnancy and predicting preterm birth. Journal of Biomedical Optics 15 0260201-02602010. (doi:10.1117/1.3381184)

Akins ML, Luby-Phelps K, Bank RA \& Mahendroo M 2011 Cervical softening during pregnancy-regulated changes in collagen cross-linking and composition of matricellular proteins in the mouse. Biology of Reproduction 84 1053-1062. (doi:10.1095/biolreprod.110.089599)

Anderson J, Brown N, Mahendroo MS \& Reese J 2006 Utilization of different aquaporin water channels in the mouse cervix during pregnancy and parturition and in models of preterm and delayed cervical ripening. Endocrinology 147 130-140. (doi:10.1210/en.2005-0896)

Andersson S, Minjarez D, Yost NP \& Word RA 2008 Estrogen and progesterone metabolism in the cervix during pregnancy and parturition. Journal of Clinical Endocrinology and Metabolism 93 2366-2374. (doi:10.1210/jc.2007-2813)

Anum EA, Hill LD, Pandya A \& Strauss JF III 2009 Connective tissue and related disorders and preterm birth: clues to genes contributing to prematurity. Placenta 30 207-215. (doi:10.1016/j.placenta.2008. 12.007)

Bornstein P \& Sage EH 2002 Matricellular proteins: extracellular modulators of cell function. Current Opinion in Cell Biology 14 608-616. (doi:10.1016/S0955-0674(02)00361-7)

Buhimschi IA, Dussably L, Buhimschi CS, Ahmed A \& Weiner CP 2004 Physical and biomechanical characteristics of rat cervical ripening are not consistent with increased collagenase activity. American Journal of Obstetrics and Gynecology 191 1695-1704. (doi:10.1016/ j.ajog.2004.03.080)

Byers BD, Bytautiene E, Costantine MM, Buhimschi CS, Buhimschi I, Saade GR \& Goharkhay N 2010 Hyaluronidase modifies the 
biomechanical properties of the rat cervix and shortens the duration of labor independent of myometrial contractility. American Journal of Obstetrics and Gynecology 203 596.e1-596.e5. (doi:10.1016/j.ajog. 2010.07.031)

Canty EG \& Kadler KE 2005 Procollagen trafficking, processing and fibrillogenesis. Journal of Cell Science 118 1341-1353. (doi:10.1242/jcs. 01731)

Condon JC, Jeyasuria P, Faust JM, Wilson JW \& Mendelson CR 2003 A decline in the levels of progesterone receptor coactivators in the pregnant uterus at term may antagonize progesterone receptor function and contribute to the initiation of parturition. PNAS 100 9518-9523. (doi:10.1073/pnas.1633616100)

Elliott CL, Brennand JE \& Calder AA 1998 The effects of mifepristone on cervical ripening and labor induction in primigravidae. Obstetrics and Gynecology 92 804-809. (doi:10.1016/S0029-7844(98)00284-1)

Elovitz MA \& Mrinalini C 2004 Animal models of preterm birth. Trends in Endocrinology and Metabolism 15 479-487. (doi:10.1016/j.tem.2004. 10.009)

Eyre DR, Paz MA \& Gallop PM 1984 Cross-linking in collagen and elastin. Annual Review of Biochemistry 53 717-748. (doi:10.1146/annurev.bi. 53.070184.003441)

Fang X, Wong S \& Mitchell BF 2002 Messenger RNA for progesterone receptor isoforms in the late-gestation rat uterus. American Journal of Physiology. Endocrinology and Metabolism 283 E1167-E1172.

Gonzalez JM, Xu H, Chai J, Ofori E \& Elovitz MA 2009 Preterm and term cervical ripening in CD1 mice (Mus musculus): similar or divergent molecular mechanisms? Biology of Reproduction 81 1226-1232. (doi:10.1095/biolreprod.108.075309)

Gonzalez JM, Franzke CW, Yang F, Romero R \& Girardi G 2011 Complement activation triggers metalloproteinases release inducing cervical remodeling and preterm birth in mice. American Journal of Pathology 179 838-849. (doi:10.1016/j.ajpath.2011.04.024)

Gordon S \& Taylor PR 2005 Monocyte and macrophage heterogeneity. Nature Reviews. Immunology 5 953-964. (doi:10.1038/nri1733)

Gross G, Imamura T, Vogt SK, Wozniak DF, Nelson DM, Sadovsky Y \& Muglia LJ 2000 Inhibition of cyclooxygenase-2 prevents inflammationmediated preterm labor in the mouse. American Journal of Physiology. Regulatory, Integrative and Comparative Physiology 278 R1415-R1423.

Harkness ML \& Harkness RD 1959 Changes in the physical properties of the uterine cervix of the rat during pregnancy. Journal of Physiology 148 524-547.

Hassan SS, Romero R, Haddad R, Hendler I, Khalek N, Tromp G, Diamond MP, Sorokin Y \& Malone J Jr. 2006 The transcriptome of the uterine cervix before and after spontaneous term parturition. American Journal of Obstetrics and Gynecology 195 778-786. (doi:10.1016/j.ajog. 2006.06.021)

Hassan SS, Romero R, Tarca AL, Nhan-Chang CL, Vaisbuch E, Erez $\mathrm{O}$, Mittal P, Kusanovic JP, Mazaki-Tovi S, Yeo L et al. 2009 The transcriptome of cervical ripening in human pregnancy before the onset of labor at term: identification of novel molecular functions involved in this process. Journal of Maternal Fetal and Neonatal Medicine 22 1183-1193. (doi:10.3109/14767050903353216)

Hirsch E \& Muhle R 2002 Intrauterine bacterial inoculation induces labor in the mouse by mechanisms other than progesterone withdrawal. Biology of Reproduction 67 1337-1341. (doi:10.1095/biolreprod67.4.1337)

Hirsch E, Filipovich Y \& Mahendroo M 2006 Signaling via the type I IL-1 and TNF receptors is necessary for bacterially induced preterm labor in a murine model. American Journal of Obstetrics and Gynecology 194 1334-1340. (doi:10.1016/j.ajog.2005.11.004)

Holt R, Timmons BC, Akgul Y, Akins ML \& Mahendroo M 2011 The molecular mechanisms of cervical ripening differ between term and preterm birth. Endocrinology 152 1036-1046. (doi:10.1210/en.20101105)

Ishida M, Choi JH, Hirabayashi K, Matsuwaki T, Suzuki M, Yamanouchi K, Horai R, Sudo K, Iwakura Y \& Nishihara M 2007 Reproductive phenotypes in mice with targeted disruption of the $20 \alpha$-hydroxysteroid dehydrogenase gene. Journal of Reproduction and Development $\mathbf{5 3}$ 499-508. (doi:10.1262/jrd.18125)

Itano N \& Kimata K 1996 Expression cloning and molecular characterization of HAS protein, a eukaryotic hyaluronan synthase. Journal of Biological Chemistry 271 9875-9878. (doi:10.1074/jbc.271.17.9875)
Jiang D, Liang J, Fan J, Yu S, Chen S, Luo Y, Prestwich GD, Mascarenhas MM, Garg HG, Quinn DA et al. 2005 Regulation of lung injury and repair by Toll-like receptors and hyaluronan. Nature Medicine 11 1173-1179. (doi:10.1038/nm1315)

Junqueira LC, Zugaib M, Montes GS, Toledo OM, Krisztan RM \& Shigihara KM 1980 Morphologic and histochemical evidence for the occurrence of collagenolysis and for the role of neutrophilic polymorphonuclear leukocytes during cervical dilation. American Journal of Obstetrics and Gynecology 138 273-281.

Kadler KE, Holmes DF, Trotter JA \& Chapman JA 1996 Collagen fibril formation. Biochemical Journal 316 1-11.

Kistka ZA, Palomar L, Boslaugh SE, DeBaun MR, DeFranco EA \& Muglia LJ 2007 Risk for postterm delivery after previous postterm delivery. American Journal of Obstetrics and Gynecology 196 241.e1-241.e6. (doi:10.1016/j.ajog.2006.10.873)

Kokenyesi R, Armstrong LC, Agah A, Artal R \& Bornstein P 2004 Thrombospondin 2 deficiency in pregnant mice results in premature softening of the uterine cervix. Biology of Reproduction 70 385-390. (doi:10.1095/biolreprod.102.014704)

Kyriakides TR, Zhu YH, Smith LT, Bain SD, Yang Z, Lin MT, Danielson KG, lozzo RV, LaMarca M, McKinney CE et al. 1998 Mice that lack thrombospondin 2 display connective tissue abnormalities that are associated with disordered collagen fibrillogenesis, an increased vascular density, and a bleeding diathesis. Journal of Cell Biology $\mathbf{1 4 0}$ 419-430. (doi:10.1083/jcb.140.2.419)

Lee HY, Zhao S, Fields PA \& Sherwood OD 2005 The extent to which relaxin promotes proliferation and inhibits apoptosis of cervical epithelial and stromal cells is greatest during late pregnancy in rats. Endocrinology 146 511-518. (doi:10.1210/en.2004-0796)

Leppert PC 1995 Anatomy and physiology of cervical ripening. Clinical Obstetrics and Gynecology 38 267-279. (doi:10.1097/00003081199506000-00009)

Liggins GC 1981 Cervical ripening as an inflammatory reaction. In The Cervix in Pregnancy and Labour, Clinical and Biochemical Investigation, Eds D Ellwood\& ABM Anderson. Edinburgh: Churchill Livingston.

Liu X, Wu H, Byrne M, Krane S \& Jaenisch R 1997 Type III collagen is crucial for collagen I fibrillogenesis and for normal cardiovascular development. PNAS 94 1852-1856. (doi:10.1073/pnas.94.5.1852)

Luque EH, Munoz de Toro MM, Ramos JG, Rodriguez HA \& Sherwood OD 1998 Role of relaxin and estrogen in the control of eosinophilic invasion and collagen remodeling in rat cervical tissue at term. Biology of Reproduction 59 795-800. (doi:10.1095/biolreprod59.4.795)

Mackler AM, lezza G, Akin MR, McMillan P \& Yellon SM 1999 Macrophage trafficking in the uterus and cervix precedes parturition in the mouse. Biology of Reproduction 61 879-883. (doi:10.1095/ biolreprod61.4.879)

Mahendroo MS, Cala KM \& Russell DW 19965 -Reduced androgens play a key role in murine parturition. Molecular Endocrinology 10 380-392. (doi:10.1210/me.10.4.380)

Mahendroo MS, Porter A, Russell DW \& Word RA 1999 The parturition defect in steroid $5 \alpha$-reductase type 1 knockout mice is due to impaired cervical ripening. Molecular Endocrinology 13 981-992. (doi:10.1210/ me.13.6.981)

Maillot KV \& Zimmermann BK 1976 The solubility of collagen of the uterine cervix during pregnancy and labour. Archiv für Gynäkologie 220 275-280. (doi:10.1007/BF00673411)

Martin JA 2011 Preterm births - United States, 2007. MMWR Surveillance Summaries 60 (Suppl) 78-79.

Maul H, Olson G, Fittkow CT, Saade GR \& Garfield RE 2003 Cervical lightinduced fluorescence in humans decreases throughout gestation and before delivery: preliminary observations. American Journal of Obstetrics and Gynecology 188 537-541. (doi:10.1067/mob.2003.94)

Mesiano S, Chan EC, Fitter JT, Kwek K, Yeo G \& Smith R 2002 Progesterone withdrawal and estrogen activation in human parturition are coordinated by progesterone receptor A expression in the myometrium. Journal of Clinical Endocrinology and Metabolism 87 2924-2930. (doi:10.1210/jc. 87.6.2924)

Midwood KS, Hussenet T, Langlois B \& Orend G 2011 Advances in tenascin-C biology. Cellular and Molecular Life Sciences 68 3175-3199. (doi:10.1007/s00018-011-0783-6)

Myers K, Socrate S, Tzeranis D \& House M 2009 Changes in the biochemical constituents and morphologic appearance of the human 
cervical stroma during pregnancy. European Journal of Obstetrics, Gynecology, and Reproductive Biology 144 (Suppl 1) S82-S89. (doi:10.1016/j.ejogrb.2009.02.008)

Myers KM, Socrate S, Paskaleva A \& House M 2010 A study of the anisotropy and tension/compression behavior of human cervical tissue. Journal of Biomechanical Engineering 132 0210031-02100315. (doi:10.1115/1.3197847)

Nold C, Anton L, Brown A \& Elovitz M 2012 Inflammation promotes a cytokine response and disrupts the cervical epithelial barrier: a possible mechanism of premature cervical remodeling and preterm birth. American Journal of Obstetrics and Gynecology 206 208.e1-208.e7. (doi:10.1016/j.ajog2011.12.036)

Osman I, Young A, Ledingham MA, Thomson AJ, Jordan F, Greer IA \& Norman JE 2003 Leukocyte density and pro-inflammatory cytokine expression in human fetal membranes, decidua, cervix and myometrium before and during labour at term. Molecular Human Reproduction 9 41-45. (doi:10.1093/molehr/gag001)

Osmers R, Rath W, Pflanz MA, Kuhn W, Stuhlsatz HW \& Szeverenyi M 1993 Glycosaminoglycans in cervical connective tissue during pregnancy and parturition. Obstetrics and Gynecology 81 88-92.

Owen J, Yost N, Berghella V, Thom E, Swain M, Dildy GA III, Miodovnik M, Langer O, Sibai B \& McNellis D 2001 Mid-trimester endovaginal sonography in women at high risk for spontaneous preterm birth. Journal of the American Medical Association 286 1340-1348. (doi:10. 1001/jama.286.11.1340)

Ozasa H, Tominaga T, Nishimura T \& Takeda T 1981 Lysyl oxidase activity in the mouse uterine cervix is physiologically regulated by estrogen. Endocrinology 109 618-621. (doi:10.1210/endo-109-2-618)

Powell JD \& Horton MR 2005 Threat matrix: low-molecular-weight hyaluronan $(\mathrm{HA})$ as a danger signal. Immunologic Research 31 207-218. (doi:10.1385/IR:31:3:207)

Rajabi MR, Solomon S \& Poole AR 1991 Biochemical evidence of collagenase-mediated collagenolysis as a mechanism of cervical dilatation at parturition in the guinea pig. Biology of Reproduction 45 764-772. (doi:10.1095/biolreprod45.5.764)

Read CP, Word RA, Ruscheinsky MA, Timmons BC \& Mahendroo MS 2007 Cervical remodeling during pregnancy and parturition: molecular characterization of the softening phase in mice. Reproduction 134 327-340. (doi:10.1530/REP-07-0032)

Robertson SA, Mau VJ, Young IG \& Matthaei KI 2000 Uterine eosinophils and reproductive performance in interleukin 5-deficient mice. Journal of Reproduction and Fertility 120 423-432. (doi:10.1530/reprod/120. 2.423)

Ruscheinsky M, De la Motte C \& Mahendroo M 2008 Hyaluronan and its binding proteins during cervical ripening and parturition: dynamic changes in size, distribution and temporal sequence. Matrix Biology 27 487-497. (doi:10.1016/j.matbio.2008.01.010)

Sakamoto Y, Moran P, Searle RF, Bulmer JN \& Robson SC 2004 Interleukin8 is involved in cervical dilatation but not in prelabour cervical ripening. Clinical and Experimental Immunology 138 151-157. (doi:10.1111/ j.1365-2249.2004.02584.x)

Sakamoto Y, Moran P, Bulmer JN, Searle RF \& Robson SC 2005 Macrophages and not granulocytes are involved in cervical ripening. Journal of Reproductive Immunology 66 161-173. (doi:10.1016/j.jri. 2005.04.005)

Spallicci MD, Chiea MA, Singer JM, Albuquerque PB, Bittar RE \& Zugaib M 2007 Use of hyaluronidase for cervical ripening: a randomized trial. European Journal of Obstetrics, Gynecology, and Reproductive Biology 130 46-50. (doi:10.1016/j.ejogrb.2005.10.028)
Spicer AP, Augustine ML \& McDonald JA 1996 Molecular cloning and characterization of a putative mouse hyaluronan synthase. Journal of Biological Chemistry 271 23400-23406. (doi:10.1074/jbc.271.38. 23400)

Stern R 2003 Devising a pathway for hyaluronan catabolism: are we there yet? Glycobiology 13 105R-115R. (doi:10.1093/glycob/cwg112)

Stjernholm-Vladic Y, Wang H, Stygar D, Ekman G \& Sahlin L 2004 Differential regulation of the progesterone receptor $A$ and $B$ in the human uterine cervix at parturition. Gynecological Endocrinology 18 41-46. (doi:10.1080/09513590310001651777)

Straach KJ, Shelton JM, Richardson JA, Hascall VC \& Mahendroo MS 2005 Regulation of hyaluronan expression during cervical ripening. Glycobiology 15 55-65. (doi:10.1093/glycob/cwh137)

Timmons BC \& Mahendroo MS 2006 Timing of neutrophil activation and expression of proinflammatory markers do not support a role for neutrophils in cervical ripening in the mouse. Biology of Reproduction 74 236-245. (doi:10.1095/biolreprod.105.044891)

Timmons BC \& Mahendroo M 2007 Processes regulating cervical ripening differ from cervical dilation and postpartum repair: insights from gene expression studies. Reproductive Sciences 14 53-62. (doi:10.1177/ 1933719107309587)

Timmons BC, Mitchell SM, Gilpin C \& Mahendroo MS 2007 Dynamic changes in the cervical epithelial tight junction complex and differentiation occur during cervical ripening and parturition. Endocrinology 148 1278-1287. (doi:10.1210/en.2006-0851)

Timmons BC, Fairhurst AM \& Mahendroo MS 2009 Temporal changes in myeloid cells in the cervix during pregnancy and parturition. Journal of Immunology 182 2700-2707. (doi:10.4049/jimmunol.0803138)

Timmons B, Akins M \& Mahendroo M 2010 Cervical remodeling during pregnancy and parturition. Trends in Endocrinology and Metabolism 21 353-361. (doi:10.1016/j.tem.2010.01.011)

Virgo BB \& Bellward GD 1974 Serum progesterone levels in the pregnant and postpartum laboratory mouse. Endocrinology 95 1486-1490. (doi:10.1210/endo-95-5-1486)

Word RA, Landrum CP, Timmons BC, Young SG \& Mahendroo MS 2005 Transgene insertion on mouse chromosome 6 impairs function of the uterine cervix and causes failure of parturition. Biology of Reproduction 73 1046-1056. (doi:10.1095/biolreprod.105.042663)

Wu D, Molofsky AB, Liang HE, Ricardo-Gonzalez RR, Jouihan HA, Bando JK, Chawla A \& Locksley RM 2011 Eosinophils sustain adipose alternatively activated macrophages associated with glucose homeostasis. Science 332 243-247. (doi:10.1126/science.1201475)

Young A, Thomson AJ, Ledingham M, Jordan F, Greer IA \& Norman JE 2002 Immunolocalization of proinflammatory cytokines in myometrium, cervix, and fetal membranes during human parturition at term. Biology of Reproduction 66 445-449. (doi:10.1095/biolreprod66.2.445)

Yu SY, Tozzi CA, Babiarz J \& Leppert PC 1995 Collagen changes in rat cervix in pregnancy - polarized light microscopic and electron microscopic studies. Proceedings of the Society for Experimental Biology and Medicine 209 360-368.

Received 5 December 2011

First decision 17 January 2012

Revised manuscript received 14 February 2012

Accepted 17 February 2012 